\title{
Dual Activation of Estrogen Receptor Alpha and Glucocorticoid Receptor Upregulate CRTh2-Mediated Type 2 Inflammation; Mechanism Driving Asthma Severity in Women?
}

\author{
Nami Shrestha Palikhe ${ }^{1}$, Meerah Vijeyakumaran ${ }^{2}$, Jenna Fortunato ${ }^{2}$, Lauren Solomon ${ }^{2}$, \\ Harissios Vliagoftis ${ }^{1}$, and Lisa Cameron ${ }^{2}$ \\ ${ }^{1}$ University of Alberta Department of Biological Sciences \\ ${ }^{2}$ Western University Department of Pathology and Laboratory Medicine
}

November 20, 2021

\begin{abstract}
Background: Type 2-high asthma is characterized by elevated levels of circulating Th2 cells and eosinophils, cells that express chemoattractant-homologous receptor expressed on Th2 cells (CRTh2). Severe asthma is more common in women than men; however, the underlying mechanism(s) remain elusive. Here we examined whether the relationship between severe asthma and type 2 inflammation differs by sex and if estrogen influences Th2 cell response to glucocorticoid (GC). Methods: Type 2 inflammation and the proportion of blood Th2 cells $\left(\mathrm{CD} 4{ }^{+} \mathrm{CRTh} 2{ }^{+}\right)$were assessed in whole blood from subjects with asthma $(\mathrm{n}=66)$. The effects of GC and estrogen receptor alpha $(\mathrm{ER} \alpha)$ agonist on in vitro differentiated Th2 cells were examined. Expression of CRTh2, type 2 cytokines and degree of apoptosis (Annexin $\mathrm{V}^{+}, 7$-AAD) were determined by flow cytometry, qRT-PCR, western blot and ELISA. Results: In severe asthma, the proportion of circulating Th2 cells and hospitalizations were higher in women than men. Women with severe asthma also had more Th2 cells and serum IL-13 than women with mild/moderate asthma. Th2 cells, eosinophils and CRTh2 mRNA correlated with clinical characteristics associated with asthma control in women but not men. In vitro, GC and ER $\alpha$ agonist treated Th2 cells exhibited less apoptosis, more CRTh2 as well as IL-5 and IL-13 following CRTh2 activation than Th2 cells treated with GC alone. Conclusion: Women with severe asthma had higher levels of circulating Th2 cells than men, which may be due to estrogen modifying the effects of GC, enhancing Th2 cell survival and type 2 cytokine production. (249)
\end{abstract}

\section{Introduction}

Asthma is a chronic inflammatory disease affecting approximately 300 million people worldwide [1]. Asthma symptoms can range from mild and manageable on low dose inhaled corticosteroids (CS) to severe and uncontrolled despite intense treatment [2]. Attempts to understand this heterogeneity have led to phenotyping asthma according to clinical, physiologic and cellular phenomena [3] and ultimately to efforts to determine the molecular mechanisms, or endotypes, driving disease [4]. Currently, at least two endotypes of severe asthma have been identified; patients exhibiting persistent type 2 inflammation with eosinophilia (type 2-high) and those with type $1 /$ type 17 inflammation with neutrophilia (type 2-low) [3].

Type 2-high asthma is characterized by increased numbers of blood and airway Th2 cells, eosinophils, group 2 innate lymphoid cells (ILC2) and type 2 cytokines IL-4, IL-5 and IL-13 [3, 4]. Woodruff et al. examined bronchial biopsies from mild-moderate asthmatics and healthy controls and showed that patients with high expression of type 2 cytokines improved following inhaled CS (ICS) treatment [5]. In type 2-high severe asthma, however, symptoms and inflammation persist despite high dose inhaled and/or oral CS $[6,7]$. Though anti-type 2 therapies are effective in these patients, indicating the pathway mediates their symptoms [2], the mechanism(s) driving persistence of type 2 inflammation remain elusive. 
Expression of CRTh2 (chemoattractant-homologous receptor expressed on Th2 cells) by CD4 ${ }^{+} \mathrm{T}$ cells is considered a marker of Th2 cells [8-10], but CRTh2 is also expressed by eosinophils, basophils, ILC2 and some $\mathrm{CD} 8^{+} \mathrm{T}$ cells [10-12]. CRTh2 is a receptor for prostaglandin $\mathrm{D}_{2}\left(\mathrm{PGD}_{2}\right)$, a lipid mediator released by mast cells within the airways following allergen-induced activation [13-15]. $\mathrm{PGD}_{2}$ activation of CRTh2 regulates Th2 cell function mediating chemotaxis, type 2 cytokine expression and inhibition of apoptosis $[10,13,16$, 17]. In murine models of asthma, CRTh2 deficiency reduced eosinophil infiltration and IL-5 production within the lung $[18,19]$. Administration of CRTh2 antagonists or depleting antibodies also showed a reduction in airway hyper-reactivity, serum IgE levels, mucus secretion and leukocyte infiltration into the airways [18, 20, 21]. CD ${ }^{+} \mathrm{CRTh} 2^{+} \mathrm{T}$ cells (i.e. Th2 cells) circulating within the blood have a memory phenotype and their frequency is considered to influence one's susceptibility to respond to subsequent allergen exposures [9, 22-24]. Although severe asthmatics have been shown to have higher levels of Th2 cells, CRTh2 mRNA and $\mathrm{PGD}_{2}$ in the blood and airways $[25,26]$, whether this pathway influences Th2 cell response to CS and/or plays a role in persistence of type 2 inflammation has not been examined.

Women are more likely to be diagnosed with severe asthma [27], to have severe exacerbations requiring hospitalization [28] and to relapse following treatment for exacerbation [29]. Serum estrogen levels have been associated with amount of IL-5 in sputum of women reporting peri-menstrual asthma symptoms [30]. $\mathrm{CD}^{+} \mathrm{T}$ cells express estrogen receptors (ER) [31] and in a mouse model of asthma estrogen administration induced expression of type 2 cytokines [32] through ER alpha $(\mathrm{ER} \alpha)$ activation [33]. Here we examined the relationship between asthma severity and type 2 inflammation in a sex-stratified analysis and assessed the ability of estrogen receptor signaling to influence Th2 cell response to in vitro exposure to CS.

\section{Methods and Materials}

Additional experimental detail is provided in the Online Supporting Material.

\section{Asthma population}

Subjects with asthma were recruited from the Asthma Clinic at the University of Alberta following written informed consent. This asthma study was approved by the University of Alberta Human Ethics Review Board (PRO1784). Lung function testing was performed and blood obtained for complete blood count (CBC), serum IgE measurement, immune cell profiling and whole blood RNA preparation. Severe asthma was defined as patients on high dose inhaled corticosteroids (ICS, [?] $1000 \mu \mathrm{g} /$ day fluticasone equivalent), a $2^{\text {nd }}$ line controller (long-acting $\beta$ agonist, leukotriene modifier, theophylline, tiotropium), anti-type 2 therapy (anti-IgE, anti-IL-5) and/or oral corticosteroid (OCS) therapy for [?] $50 \%$ of the previous year whose symptoms remain uncontrolled despite this therapy [2].

\section{Flow cytometry}

Circulating Th2 cells were assessed as the proportion of peripheral blood CD4 ${ }^{+} \mathrm{T}$ cells expressing CRTh2 as we described previously $[26,34]$ (Fig. S1). CRTh2 levels on in vitro differentiated Th2 cells were determined as previously referenced [35] (Fig. S2). Briefly, cells were stained using antibodies against CD4, CRTh2 or isotype control and fixed with paraformaldehyde (2\%). Flow cytometry analysis was performed using a BD LSR II Flow Cytometer, with gates set in accordance with the profiles of the isotype control and/or negative control beads. Results were analyzed using FlowJo ${ }^{\circledR}$ (TreeStar, Ashland OR, USA).

\section{In vitro differentiated Th2 cells}

Th2 cells were differentiated from peripheral blood $\mathrm{CD} 4^{+} \mathrm{T}$ cells, as we previously described [35]. $\mathrm{CRTh} 2^{+} \mathrm{CD} 4^{+} \mathrm{T}$ cells (Th2 cells) were maintained $\left(2 \times 10^{6}\right.$ cells $\left./ \mathrm{mL}\right)$ on cycles of IL-2 $(5-10 \mathrm{ng} / \mathrm{mL})$ and plate bound antibody against CD3 and CD28 (3 days, $1 \mu \mathrm{g} / \mathrm{ml}$ ) followed by IL-2 alone (4 days). For experiments with glucocorticoid and estrogen, primary Th2 cells $\left(1.3 \times 10^{6}\right.$ cells $\left./ \mathrm{mL}\right)$ were treated (24 hours) with dexamethasone (DEX), the ER $\alpha$ agonist propyl pyrazole triol (PPT) or $\beta$-estradiol (E2). To assess Th2 cell response to CRTh2 activation, Th2 cells were pre-treated with DEX and/or PPT (24 hours), washed and re-plated with $\mathrm{PGD}_{2}$ (24 hours). Thesein vitro experiments were approved by the Ethics Review Boards at the University of Alberta (00000942) and Western University (106770). 


\section{Western blot analysis}

Primary Th2 cells were harvested in lysis buffer and protein electrophoresed on SDS-Page gel. Gels were wet transferred onto nitrocellulose membrane, blocked with milk (Carnation skim milk powder, $5 \%$ ) and incubated with antibody against CRTh2. Membranes were washed in TBS-T and incubated with horseradish peroxidase secondary antibody. Bands were detected using Clarity Western ECL substrate (Bio-Rad, CA, USA) and images were acquired using a ChemiDoc MP Imaging System. GAPDH was detected after stripping the membranes and re-probing with antibody against GAPDH. Densitometry of CRTh2 was normalized to GAPDH using ImageJ.

Quantitative real time ( $q R T)-P C R$

Whole blood was collected in PaxGene tubes and RNA isolated according to manufacturer's instruction. RNA was isolated from in vitrodifferentiated Th2 cells using RNeasy MiniKit. Levels of CRTh2 and BCL-2 mRNA were determined using TaqMan assays, expressed relative to GAPDH and fold change from control.

\section{CRTh2 promoter activity}

CRTh2 pro-Luc, a luciferase reporter construct containing an 1836 base pair fragment of the CRTH2 promoter, was transiently co-transfected along with a minimal constitutively active thymidine kinase renilla control plasmid (pRL-TK) into CCRF-CEM cells as described [35]. Cells were treated with DEX in the presence or absence of PPT (22 hours), pelleted, resuspended in lysis buffer $(250 \mu \mathrm{l})$, subjected to freeze/thaw and $10 \mu \mathrm{L}$ of sample analyzed using Dual-Luciferase Reporter Assay. Protein concentrations were measured and results expressed as relative luciferase units (RLU), normalized for transfection efficiency and protein concentration.

Enzyme-linked immunosorbent assay (ELISA)

Cell culture supernatants were collected following $\mathrm{PGD}_{2}$ stimulation (24 hours) and cytokine concentration determined using ELISA for IL-5 and IL-13 according to the manufacturer's instructions. Samples were measured in triplicate and were all within the range of the standard curve.

\section{Statistical Analysis}

Descriptive data for clinical characteristics between men and women and between mild/moderate and severe asthma are reported using proportions for dichotomous variables or means (Min-Max) for continuous variables, as appropriate. Bivariable comparisons of dichotomous variables are performed using chi-squared $\left(\chi^{2}\right)$ test whereas Mann-Whitney U test are performed for continuous variables. Statistical analyses were performed using SPSS (version 21.1, Chicago, IL, USA) and R (R Team, 2020). As multiple statistical tests were performed on the clinical data, $P$-values less than 0.01 were considered statistically significant. For $i n$ vitro experiments with Th2 cells statistical significance between conditions was determined using One Way Repeated Measures (RM) ANOVA with Student-Newman-Keuls for multiple comparisons. $P$-values less than 0.05 were considered significant.

\section{Results}

\section{Demographics and clinical characteristics}

Subjects $(\mathrm{n}=66)$ were recruited and clinically characterized to assess asthma severity. Some results from this cohort have been previously reported [26]. Here we present additional demographic, clinical and immune data separated by sex (Table 1$)$. Men had a lower ratio of forced expiratory volume in one second $\left(\mathrm{FEV}_{1}\right)$ over forced vital capacity (FVC) and a higher proportion of men had $\mathrm{FEV}_{1}$ (\% predicted) below $80 \%$. No differences in type 2 inflammation were observed when asthmatics were stratified by sex only (Table 1).

Th2 cells are higher in women, but not men, with severe asthma 
Examining asthmatics stratified by sex and severity showed, as expected, both women and men with severe asthma were taking higher daily doses of ICS than those with mild/moderate disease (Table 2). Women with severe asthma, however, were more likely to be hospitalized for their asthma, to have more neutrophils, higher serum IL-13 and more circulating peripheral blood Th2 cells than women with mild/moderate asthma (Table 2, Fig. 1A). In contrast, comparison of men with mild/moderate and severe asthma showed no differences in type 2 inflammation (Table 2, Fig. 1A). Women with severe asthma had more hospitalizations and higher proportions of circulating Th2 cells than men with severe asthma (Table 2; Fig. 1A). Women also had more Th2 cells when those on oral CS ( $>50 \%$ of the year) or anti-type 2 biologic therapy (anti-IgE or anti-IL-5) were removed from the analysis (Fig. 1B). Though men and women with asthma were taking similar amounts of ICS (Table 1), only women exhibited positive correlations between total daily dose of ICS and circulating Th2 cells, while CRTh2 mRNA and eosinophils (Fig. 1C, 1E and Table S1) were inversely correlated with $\mathrm{FEV}_{1}$ (Fig. 1G). No relationships between these parameters were observed in men (Figs. 1D, F, H). Collectively, these observations suggest that asthma severity in women associates with type 2 inflammation.

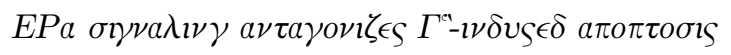

Corticosteroids used to treat asthma mediate their effects by binding the glucocorticoid (GC) receptor (GR) [36]. A major anti-inflammatory effect of GC is the ability to induce apoptosis, clearing inflammatory cells from sites of exposure and the circulation [37, 38]. Our finding that the level of circulating Th2 cells correlated with total daily dose of ICS in women, but not men, suggested that aspects of female biology may influence GC responses. Since estrogen can inhibit apoptosis of Th2 cells [39-41], we first hypothesized that estrogen receptor (ER) activation would decrease Th2 cell sensitivity to GC-induced apoptosis. Using primary in vitro differentiated Th2 cells, we examined the effect of various concentrations of the GC dexamethasone (DEX)

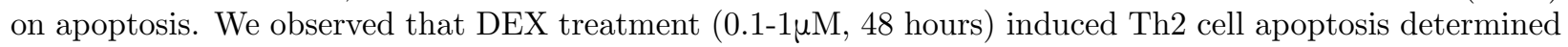
by Annexin $\mathrm{V}$ positivity and 7AAD negativity (Annexin V+/7AAD-, Fig. 2A). Concomitant exposure to DEX and the ER $\alpha$ selective agonist propyl pyrazole triol (PPT) resulted in significantly less apoptosis at all concentrations, with the greatest reduction at 0.1 $\mu \mathrm{M}$ DEX (Fig. 2A). Similar results were observed

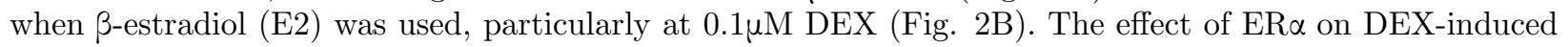
apoptosis was also confirmed by staining with fluorochrome-labeled inhibitor of caspase (FLICA, Fig. S3). Apoptosis occurs when pores are formed in the mitochondrial membrane, allowing release of cytochrome $\mathrm{c}$ [42]. B cell lymphoma-2 (BCL-2) inhibits pore formation [43] and has been shown to be induced by ER signaling [41]. We found that Th2 cells treated with DEX alone exhibited a small but significant increase in BCL-2 mRNA, likely an attempt by the Th2 cells to counteract apoptosis [44]. Addition of both DEX and PPT, however, resulted in significantly higher levels of BCL-2 mRNA than DEX alone ( ${ }^{1.8}$-fold at $0.1 \mu \mathrm{M}$ DEX; Fig. 2C). These results suggest that combined signaling of GC and ER $\alpha$ increases the level of the anti-apoptotic factor BCL-2, leading to enhanced Th2 cell survival. The other major effect of GC action is their ability to suppress type 2 cytokine production $[45,46]$. We found that Th2 cells treated with DEX exhibited suppression of constitutive IL-5 and IL-13 mRNA levels. Unlike apoptosis, suppression of constitutive cytokine levels was not antagonized by PPT (Fig. 2D) suggesting multiple mechanisms by which $\mathrm{ER} \alpha$ signaling influences GC action.

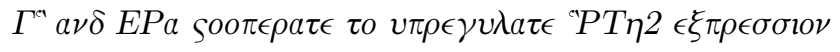

Total daily dose of ICS correlated with whole blood levels ofCRTh2 mRNA in women, but not men (Fig. $1 \mathrm{E}, 1 \mathrm{~F})$. Therefore, we next examined whether GC and ER $\alpha$ signaling directly influences CRTh2 expression. Th2 cells treated with both DEX and PPT (24 hours) exhibited significantly more CRTh2 mRNA compared to vehicle or DEX alone (Fig. 3A). Western blot analysis showed higher abundance of total CRTh2 protein following co-treatment with PPT and DEX (Fig. 3B). CRTh2 is a plasma membrane receptor and so we assessed surface levels by flow cytometry and found CRTh2 was significantly increased following cotreatment with DEX and PPT (Fig. 3C) or DEX and E2 (Fig. 3D). Upregulation of CRTh2 was likely due to a transcriptional effect since the CRTh2 promoter construct contains putative GC response elements (GRE) and activity was increased by DEX treatment alone and further enhanced with both DEX and PPT 
(24 hours, Fig. 3E). Together, these experiments show that concomitant activation of GR and ER $\alpha$ increases CRTh2 expression.

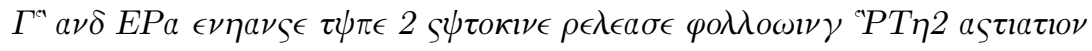

Since concomitant DEX and PPT treatment increased CRTh2 expression (Fig. 3), we considered whether this exposure primed Th2 cells for heightened responsiveness to $\mathrm{PGD}_{2}$. Th2 cells were pre-treated with DEX alone or DEX and PPT (24 hours), washed and stimulated with $\mathrm{PGD}_{2}$ (24 hours) to activate the cells through CRTh2. We found that while pre-treatment with DEX alone reduced both cytokines, Th2 cells pre-treated with DEX and PPT released significantly more IL-5 (Fig. 4A) and IL-13 (Fig. 4B) in response to $\mathrm{PGD}_{2}$ compared to DEX alone or no pre-treatment. These results suggest that the cooperative effect of GC and ER $\alpha$ on CRTh2 levels enhances the Th2 cell response to $\mathrm{PGD}_{2}$, increasing type 2 cytokine release.

\section{Discussion}

In childhood, asthma is more common in boys than girls but after puberty the prevalence shifts such that twice as many women have asthma as men [47]. The timing of this shift suggests a role for rising levels of female sex hormones such as estrogens, shown to mediate type 2 cytokine expression [32, 48]. We found that women with severe asthma had more circulating Th2 cells than men despite similar amounts of ICS. We reasoned that in these women Th2 cells may be either less sensitive to the anti-inflammatory effects of GC or more readily activated. Our in vitro data support both hypotheses, indicating that in vivo estrogens may interfere with the ability of GC therapies to eliminate Th2 cells as well as promote CRTh2 expression, mediating type 2 inflammation.

Women are more likely than men to have severe asthma and to experience asthma exacerbations and emergency department visits $[27,29,49]$. Our study suggests these longstanding observations may relate to differences in type 2 inflammation since women with severe asthma had more circulating Th2 cells and hospitalizations than severe asthmatic men despite similar ICS usage. This finding contrasts with Aw et al. who found no difference in type 2 inflammation between severe asthmatic women and men [50]. The reason for this discrepancy may lie in the severity of the asthma population and/or asthma management. Our study cohort had only a few patients on OCS for more than $50 \%$ of the year (7.5\%), while all the patients in Aw et al. required OCS for 6 months or more [50], which may have suppressed differences in systemic inflammation [51]. Studies have shown women with mild asthma to have more sputum ILC2s than men prior to and after allergen challenge [50] and women with severe asthma to have more blood ILC2s than men [52]. Neither, however, reported differences in the proportion of circulating Th2 cells nor assessed the relationship between type 2 inflammation and asthma severity across a heterogeneous asthma population. Our findings that blood Th2 cells, eosinophils and CRTh2 mRNA correlated with clinical characteristics associated with asthma severity (ICS and $\mathrm{FEV}_{1}$ ) in women but not men suggests differences in sensitivity to ICS therapy and/or propensity for type 2 inflammation.

Several human studies have reported females experiencing less improvement on ICS than males (reviewed in [53]). This may be driven by crosstalk between GR and ER $\alpha$, known to result in antagonistic or cooperative effects in a gene-dependent manner $[54,55]$. Our in vitro studies suggest both mechanisms are at play. The ability of GC to induce apoptosis was decreased by ER $\alpha$ signaling. This was related to ER $\alpha$ enhancing the anti-apoptotic response, upregulating BCL-2, and suggests that in vivo estrogens may antagonize this anti-inflammatory aspect of GC function, perpetuating type 2 inflammation. On the other hand, our study is the first to report that GC and $\mathrm{ER} \alpha$ agonist cooperate to upregulate CRTh2 expression. The CRTh2 promoter contains putative GC response elements (GRE) and so the ER $\alpha$ enhancing effect may be related to its ability to stabilize GR binding [55, 56], increasing CRTh2 transcriptional activity. That increases in CRTh2 mRNA and protein were observed only with co-treatment suggests the timing of analysis may have failed to capture a GC-mediated effect and/or that ER $\alpha$ also influences mRNA stability and translation of CRTh2. Although we focused on Th2 cells, CRTh2 is expressed by eosinophils, basophils and ILC2 [10, 11] and so CRTh2 mRNA levels detected within the blood may collectively reflect expression by all these cell types. 
The GC and ER $\alpha$ mediated increase in CRTh2 levels enhanced Th2 cell response to $\mathrm{PGD}_{2}$, significantly increasing IL-5 and IL-13 release. Since CRTh2 activation also mediates chemotaxis [10, 13, 57], this interaction may lead to more CRTh2 expressing cells infiltrating the airways following mast cell release of $\mathrm{PGD}_{2}[15,58,59]$. Though further work is needed to determine whether type 2 inflammation within the airways is also higher in women compared to men with severe asthma, this paradoxical pro-type 2 effect of GC treatment has been previously reported within the airways of female mice [60,61]. Together these studies suggest that in vivo estrogen and GC interaction could drive persistence of type 2 inflammation by upregulating the CRTh2 pathway, leading to asthma that is more difficult to treat in women.

Studies examining sex differences in autoimmune disease consistently report that females have higher CD4 ${ }^{+}$ $\mathrm{T}$ cell counts, CD4 ${ }^{+} \mathrm{T}$ cell activity and greater antibody responses [62]. As such, our finding likely represents only the tip of the iceberg in terms of how immune responses in asthma differ based on biological sex [63]. Mouse models show females mounting stronger type 2 responses than males [52, 64, 65] and that sex hormones have opposing effects on type 2 inflammation. In female mice estrogens induced type 2 inflammation through $\mathrm{ER} \alpha$ signaling [66], while in males androgen hormones inhibited development of type 2 inflammation [52, 64]. A head-to-head comparison of gonadectomy showed that loss of androgens in males lead to higher type 2 inflammation, while loss of ovarian hormones in females lowered levels of type 2 inflammation [65]. Sex hormones may also have cell type-specific effects, since androgen receptor mutant mice showed reduced IL-13 or GATA levels in ILC2s, but not in Th2 cells [65], while estrogen receptor signaling increased T cell production of IL-4 and GATA3 [33]. Ultimately, these studies suggest type 2 inflammation may develop in a sex- and cell type-specific manner involving different pathways, similar to mechanical pain hypersensitivity shown to be mediated by microglial cells in male mice and $\mathrm{T}$ cells in female mice [67].

Our study reveals the capacity of estrogen to enhance GC-induction of CRTh2 and the propensity of Th2 cells to release IL-5 and IL-13. In vivo the higher estrogen levels in women than men (nM vs pM) interacting with ICS, could explain our clinical observation of persistent type 2 inflammation in severe asthmatic women. This induction of CRTh2 would likely increase infiltration of both Th2 cells and ILC2, which may synergize locally with the ability of ER $\alpha$ to control ILC2s through epithelial expression of IL-33 [68]. Other mechanisms, however, may also be involved. Androgens have been shown to suppress type 2 inflammation [64], their levels to correlate with better lung function in both men and women [69] and to be influenced by genetic variation

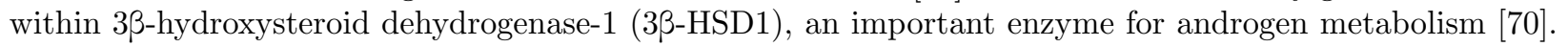
As such, we cannot rule out the possibility that severe asthma in women could also involve having lower androgen levels and/or AR signaling. Future studies in human asthmatics are required to determine the relationship between sex hormone levels, type 2 cells and response to GC therapy and will need to be specifically designed to account for age/stage of life (menstruation to menopause), phase of the monthly menstrual cycle and oral contraceptive use. Our findings call for examination of whether women have higher ICS requirements to control type 2 inflammation. Moreover, studies assessing CRTh2 levels as a systemic indicator of persistent type 2 inflammation could help optimize ICS therapy and/or identify patients most likely responsive to anti-type 2 biologics.

In summary, we report that women with severe asthma had higher circulating levels of Th2 cells than men with severe asthma. Ourin vitro data show this could be attributed to estrogen and GC interactions enhancing CRTh2-mediated type 2 inflammation. Sex-stratified approaches may be necessary to fully unravel the complexity of type 2-high severe asthma.

\section{Acknowledgments}

The authors would like to thank Angela Hillaby, Miranda Bowen and Dr. Cheryl Laratta for their work coordinating and gathering the clinical data. We would also like to thank Darya Abdolmaleki and Jerusha Raveendraraj for their help creating flow cytometry figures for in vitro differentiated Th2 cells. The authors would also like thank Dr. Brian Rowe and Dr. Michaela Schedel for critical review of the manuscript.

\section{Funding Sources}

This work would not be possible without operating grant support from the Canadian Institutes of Health 
Research (CIHR) to Drs. L. Cameron and H. Vliagoftis, a Canadian Allergy Asthma and Immunology Foundation (CAAIF) Fellowship to Dr. L. Solomon and grants-in-aid to Dr. L. Cameron from CAAIF and Western University.

\section{Conflict of Interest}

The authors have no conflicts of interest to declare.

\section{Author Contributions}

MV participated in study design and performed experiments with primary differentiated Th2 cells using flow cytometry, qRT-PCR, Western blot and ELISA and prepared the first draft of the manuscript. JF contributed to flow cytometry experiments and performed the luciferase assays. LS performed qRT-PCR, supported Western blot and ELISA experiments and helped prepare figures for the manuscript. NSP performed flow cytometry on blood from asthmatics, performed data analysis helped prepare figures for the manuscript. HV supervised data collection and reviewed the final draft of the manuscript. LC was responsible for study design, supervised data collection, and authored the final draft of the manuscript. All authors read and approved the final manuscript.

\section{References}

1. Braman, S.S., The global burden of asthma. Chest, 2006. 130 (1 Suppl): p. 4S-12S.

2. Chung, K.F., et al.,International ERS/ATS guidelines on definition, evaluation and treatment of severe asthma. Eur Respir J, 2014. 43 (2): p. 343-73.

3. Wenzel, S.E., Asthma phenotypes: the evolution from clinical to molecular approaches. Nat Med, 2012. 18 (5): p. 716-25.

4. Fahy, J.V., Type 2 inflammation in asthma-present in most, absent in many. Nat Rev Immunol, 2015. 15 (1): p. 57-65.

5. Woodruff, P.G., et al., T-helper type 2-driven inflammation defines major subphenotypes of asthma. Am J Respir Crit Care Med, 2009. 180 (5): p. 388-95.

6. Busse, W.W., S. Banks-Schlegel, and S.E. Wenzel, Pathophysiology of severe asthma. J Allergy Clin Immunol, 2000. 106 (6): p. 1033-42.

7. Kostikas, K., E. Zervas, and M. Gaga, Airway and systemic eosinophilia in asthma: does site matter? Eur Respir J, 2014. 44 (1): p. 14-6.

8. Cosmi, L., et al., CRTH2 is the most reliable marker for the detection of circulating human type 2 Th and type 2 T cytotoxic cells in health and disease. Eur J Immunol, 2000. 30 (10): p. 2972-9.

9. Wambre, E., et al., A phenotypically and functionally distinct human TH2 cell subpopulation is associated with allergic disorders. Sci Transl Med, 2017.9 (401).

10. Nagata, K., et al., CRTH2, an orphan receptor of T-helper-2-cells, is expressed on basophils and eosinophils and responds to mast cell-derived factor(s). FEBS Lett, 1999. 459 (2): p. 195-9.

11. Mjösberg, J. and H. Spits, Type 2 innate lymphoid cells-new members of the "type 2 franchise" that mediate allergic airway inflammation. Eur J Immunol, 2012.42 (5): p. 1093-6.

12. Tsuda, H., et al., A novel surface molecule of Th2- and Tc2-type cells, CRTH2 expression on human peripheral and decidual $C_{4}+$ and $C D 8+T$ cells during the early stage of pregnancy. Clin Exp Immunol, 2001. 123 (1): p. 105-11.

13. Hirai, H., et al.,Prostaglandin D2 selectively induces chemotaxis in Thelper type 2 cells, eosinophils, and basophils via seven-transmembrane receptor CRTH2. J Exp Med, 2001. 193 (2): p. 255-61. 
14. Murata, T. and T. Maehara,Discovery of anti-inflammatory role of prostaglandin D. J Vet Med Sci, 2016. 78 (11): p. 1643-1647.

15. Wenzel, S.E., et al.,Spectrum of prostanoid release after bronchoalveolar allergen challenge in atopic asthmatics and in control groups. An alteration in the ratio of bronchoconstrictive to bronchoprotective mediators. Am Rev Respir Dis, 1989. 139 (2): p. 450-7.

16. Xue, L., et al.,Prostaglandin D2 causes preferential induction of proinflammatory Th2 cytokine production through an action on chemoattractant receptor-like molecule expressed on Th2 cells. J Immunol, 2005.175 (10): p. 6531-6.

17. Xue, L., A. Barrow, and R. Pettipher, Novel function of CRTH2 in preventing apoptosis of human Th2 cells through activation of the phosphatidylinositol 3-kinase pathway. J Immunol, 2009. 182 (12): p. 7580-6.

18. Satoh, T., et al.,Prostaglandin D2 plays an essential role in chronic allergic inflammation of the skin via CRTH2 receptor. J Immunol, 2006.177 (4): p. 2621-9.

19. Nomiya, R., et al., CRTH2 plays an essential role in the pathophysiology of Cry $j$ 1-induced pollinosis in mice. J Immunol, 2008. 180 (8): p. 5680-8.

20. Lukacs, N.W., et al., CRTH2 antagonism significantly ameliorates airway hyperreactivity and downregulates inflammation-induced genes in a mouse model of airway inflammation. Am J Physiol Lung Cell Mol Physiol, 2008.295 (5): p. L767-79.

21. Huang, T., et al.,Depletion of major pathogenic cells in asthma by targeting CRTh2.JCI Insight, 2016. 1 (7): p. e86689.

22. Messi, M., et al., Memory and flexibility of cytokine gene expression as separable properties of human $T(H) 1$ and $T(H) 2$ lymphocytes. Nat Immunol, 2003. 4 (1): p. 78-86.

23. Bredo, G., et al.,Interleukin-25 initiates Th2 differentiation of human CD4(+) T cells and influences expression of its own receptor. Immun Inflamm Dis, 2015. 3 (4): p. 455-68.

24. Mojtabavi, N., et al.,Long-lived Th2 memory in experimental allergic asthma. J Immunol, 2002. 169 (9): p. $4788-96$.

25. Fajt, M.L., et al.,Prostaglandin D2 pathway upregulation: relation to asthma severity, control, and TH2 inflammation. J Allergy Clin Immunol, 2013.131 (6): p. 1504-12.

26. Palikhe, N.S., et al.,Elevated levels of circulating CD4(+) CRTh2 $(+)$ T cells characterize severe asthma. Clin Exp Allergy, 2016. 46 (6): p. 825-36.

27. The ENFUMOSA cross-sectional European multicentre study of the clinical phenotype of chronic severe asthma. European Network for Understanding Mechanisms of Severe Asthma. Eur Respir J, 2003. 22 (3): p. $470-7$.

28. Schatz, M., et al., Asthma exacerbation rates in adults are unchanged over a 5-year period despite high-intensity therapy. J Allergy Clin Immunol Pract, 2014.2 (5): p. 570-4.e1.

29. Hill, J., et al., Factors associated with relapse in adult patients discharged from the emergency department following acute asthma: a systematic review. BMJ Open Respir Res, 2017. 4 (1): p. e000169.

30. Semik-Orzech, A., S. Skoczyński, and W. Pierzchała, Serum estradiol concentration, estradiol-toprogesterone ratio and sputum IL-5 and IL-8 concentrations are increased in luteal phase of the menstrual cycle in perimenstrual asthma patients. Eur Ann Allergy Clin Immunol, 2017. 49 (4): p. 161-170.

31. Phiel, K.L., et al.,Differential estrogen receptor gene expression in human peripheral blood mononuclear cell populations. Immunol Lett, 2005. 97 (1): p. 107-13. 
32. Cai, Y., J. Zhou, and D.C. Webb,Estrogen stimulates Th2 cytokine production and regulates the compartmentalisation of eosinophils during allergen challenge in a mouse model of asthma. Int Arch Allergy Immunol, 2012. 158 (3): p. 252-60.

33. Lambert, K.C., et al.,Estrogen receptor alpha (ERalpha) deficiency in macrophages results in increased stimulation of CD4+ T cells while 17beta-estradiol acts through ERalpha to increase IL-4 and GATA-3 expression in $C D_{4}+T$ cells independent of antigen presentation. J Immunol, 2005.175 (9): p. 5716-23.

34. Shrestha Palikhe, N., et al., Th2 cell markers in peripheral blood increase during an acute asthma exacerbation. Allergy, 2021. 76 (1): p. 281-290.

35. MacLean Scott, E., et al.,Activation of Th2 cells downregulates CRTh2 through an NFAT1 mediated mechanism. PLoS One, 2018. 13 (7): p. e0199156.

36. Johnson, M., Development of fluticasone propionate and comparison with other inhaled corticosteroids. J Allergy Clin Immunol, 1998. 101 (4 Pt 2): p. S434-9.

37. Melis, M., et al.,Fluticasone induces apoptosis in peripheral T-lymphocytes: a comparison between asthmatic and normal subjects. Eur Respir J, 2002.19 (2): p. 257-66.

38. Zhang, X., E. Moilanen, and H. Kankaanranta, Enhancement of human eosinophil apoptosis by fluticasone propionate, budesonide, and beclomethasone. Eur J Pharmacol, 2000. 406 (3): p. 325-32.

39. Lewis-Wambi, J.S. and V.C. Jordan, Estrogen regulation of apoptosis: how can one hormone stimulate and inhibit? Breast Cancer Res, 2009. 11 (3): p. 206.

40. Grott, M., et al.,Progesterone and estrogen prevent cisplatin-induced apoptosis of lung cancer cells. Anticancer Res, 2013. 33 (3): p. 791-800.

41. Huber, S.A., J. Kupperman, and M.K. Newell, Estradiol prevents and testosterone promotes Fasdependent apoptosis in CD4+ Th2 cells by altering Bcl 2 expression.Lupus, 1999. 8 (5): p. 384-7.

42. Liu, X., et al., Induction of apoptotic program in cell-free extracts: requirement for dATP and cytochrome c. Cell, 1996. 86 (1): p. 147-57.

43. Cheng, E.H., et al., BCL-2, BCL-X(L) sequester BH3 domain-only molecules preventing BAX- and BAK-mediated mitochondrial apoptosis. Mol Cell, 2001. 8 (3): p. 705-11.

44. Ploner, C., et al., The BCL2 rheostat in glucocorticoid-induced apoptosis of acute lymphoblastic leukemia. Leukemia, 2008. 22 (2): p. 370-7.

45. Gemou-Engesaeth, V., et al.,Inhaled glucocorticoid therapy of childhood asthma is associated with reduced peripheral blood $T$ cell activation and 'Th2-type' cytokine mRNA expression. Pediatrics, 1997. 99 (5): p. 695-703.

46. Jee, Y.K., et al.,Repression of interleukin-5 transcription by the glucocorticoid receptor targets GATA3 signaling and involves histone deacetylase recruitment. J Biol Chem, 2005. 280 (24): p. 23243-50.

47. Zein, J.G. and S.C. Erzurum,Asthma is Different in Women. Curr Allergy Asthma Rep, 2015.15 (6): p. 28.

48. Salem, M.L., Estrogen, a double-edged sword: modulation of TH1- and TH2-mediated inflammations by differential regulation of TH1/TH2 cytokine production. Curr Drug Targets Inflamm Allergy, 2004. 3 (1): p. 97-104.

49. Schatz, M. and C.A. Camargo, The relationship of sex to asthma prevalence, health care utilization, and medications in a large managed care organization. Ann Allergy Asthma Immunol, 2003. 91 (6): p. 553-8.

50. Aw, M., et al., Effect of sex on group 2 innate lymphoid cells in the airways of mild and severe asthmatics. Allergy, 2019. 74 (7): p. 1397-1400. 
51. Oehling, A.G., et al.,Suppression of the immune system by oral glucocorticoid therapy in bronchial asthma. Allergy, 1997. 52 (2): p. 144-54.

52. Cephus, J.Y., et al., Testosterone Attenuates Group 2 Innate Lymphoid Cell-Mediated Airway Inflammation. Cell Rep, 2017. 21 (9): p. 2487-2499.

53. Hunninghake, G.M. and D.R. Gold,Sexual dimorphism: Is it relevant to steroid resistance or asthma control? J Allergy Clin Immunol, 2009. 124 (4): p. 688-90.

54. Cvoro, A., et al., Cross talk between glucocorticoid and estrogen receptors occurs at a subset of proinflammatory genes. J Immunol, 2011. 186 (7): p. 4354-60.

55. West, D.C., et al., GR and ER Coactivation Alters the Expression of Differentiation Genes and Associates with Improved ER+ Breast Cancer Outcome. Mol Cancer Res, 2016. 14 (8): p. 707-19.

56. Miranda, T.B., et al.,Reprogramming the chromatin landscape: interplay of the estrogen and glucocorticoid receptors at the genomic level. Cancer Res, 2013.73 (16): p. 5130-9.

57. Xue, L., et al.,Prostaglandin D2 activates group 2 innate lymphoid cells through chemoattractant receptorhomologous molecule expressed on TH2 cells. J Allergy Clin Immunol, 2014. 133 (4): p. 1184-94.

58. Lewis, R.A., et al.,Prostaglandin D2 generation after activation of rat and human mast cells with antiIgE. J Immunol, 1982. 129 (4): p. 1627-31.

59. Obata, T., et al.,IgE-anti-IgE-induced prostaglandin D2 release from cultured human mast cells. Biochem Biophys Res Commun, 1996. 225 (3): p. 1015-20.

60. Wiley, R.E., et al., Transient corticosteroid treatment permanently amplifies the Th2 response in a murine model of asthma. J Immunol, 2004. 172 (8): p. 4995-5005.

61. Southam, D.S., et al., Goblet cell rebound and airway dysfunction with corticosteroid withdrawal in a mouse model of asthma. Am J Respir Crit Care Med, 2008.178 (11): p. 1115-22.

62. Klein, S.L. and K.L. Flanagan,Sex differences in immune responses. Nat Rev Immunol, 2016.16 (10): p. $626-38$.

63. Shah, R. and D.C. Newcomb,Sex Bias in Asthma Prevalence and Pathogenesis. Front Immunol, 2018. 9: p. 2997.

64. Laffont, S., et al.,Androgen signaling negatively controls group 2 innate lymphoid cells. J Exp Med, 2017. 214 (6): p. 1581-1592.

65. Fuseini, H., et al., Testosterone Decreases House Dust Mite-Induced Type 2 and IL-17A-Mediated Airway Inflammation. J Immunol, 2018. 201 (7): p. 1843-1854.

66. Keselman, A. and N. Heller,Estrogen Signaling Modulates Allergic Inflammation and Contributes to Sex Differences in Asthma. Front Immunol, 2015. 6 : p. 568.

67. Sorge, R.E., et al.,Different immune cells mediate mechanical pain hypersensitivity in male and female mice. Nat Neurosci, 2015. 18 (8): p. 1081-3.

68. Cephus, J.Y., et al.,Estrogen receptor-alpha signaling increases allergen-induced IL-33 release and airway inflammation. Allergy, 2021. 76 (1): p. 255-268.

69. Zein, J.G., et al.,Benefits of Airway Androgen Receptor Expression in Human Asthma.Am J Respir Crit Care Med, 2021.

70. Zein, J., et al., HSD3B1 genotype identifies glucocorticoid responsiveness in severe asthma.Proc Natl Acad Sci U S A, 2020. 117 (4): p. 2187-2193.

Figure Legends 
Figure 1 Th2 inflammation is higher in women than men with severe asthma Proportion of circulating Th2 cells $\left(\mathrm{CD} 4^{+} \mathrm{CRTh} 2^{+} \mathrm{T}\right.$ cells/pWBC) in men and women with mild/moderate and severe asthma was assessed by flow cytometry (A). Proportion of circulating Th2 cells in severe asthmatic men and women not taking OCS or biologics (anti-IgE or IL-5; B). Correlation analyses between the proportion of circulating Th2 cells and total daily dose of ICS in women (C) and men (D), whole blood CRTh2 mRNA (relative to GAPDH) and ICS in women (E) and men (F) and CRTh2 mRNA and FEV 1 (\% predicted) in women $(\mathrm{G})$ and men (H).pWBC, peripheral white blood cells; ICS , inhaled corticosteroid oral corticosteroid; OCS , oral corticosteroid, $F E V_{1}$, forced expiratory volume in 1 second. $^{*} P<0.01$ determined by One Way ANOVA $(\mathrm{A}),{ }^{*} P=0.016$ two-tailed Student's t test (B)

Figure 2 Estrogen receptor signaling decreases Th2 cell sensitivity to GC-induced apoptosis In vitro differentiated Th2 cells treated with DEX and either the ER $\alpha$ selective agonist PPT $(1 \mu \mathrm{M}, \mathrm{A})$ or DEX and $\beta$-estradiol $(0.1 \mu \mathrm{M}, \mathrm{E} 2$; B) were assessed for apoptosis by flow cytometry using Annexin $\mathrm{V}$ positivity in the absence of 7 -AAD staining (Annexin $\mathrm{V}^{+} / 7-\mathrm{AAD}^{-}$). Level of BCL-2 mRNA (relative to GAPDH) was elevated by qRT-PCR in Th2 cells treated with DEX and PPT (C). Constitutive levels of mRNA for IL-5 and IL-13 from Th2 cells treated with Vehicle, DEX and/or PPT (D; 24 hours).GC, glucocorticoid; DEX , dexamethasone; $P P T$, propyl pyrazole triol (ER $\alpha$ selective agonist); $E P \alpha$, estrogen receptor alpha; $I L-5$, Interleukin $5 ; I L-13$, Interleukin $13 .^{*} P<0.05$ vs vehicle; $\# P<0.05$ vs DEX, determined by One Way RM ANOVA

Figure 3 Combined GC and estrogen receptor signaling upregulates CRTh2 expression. Effect of treating in vitrodifferentiated Th2 cells with DEX $(0.1 \mu \mathrm{M})$ and/or PPT $(10 \mu \mathrm{M})$ was assessed at the level of CRTh2 mRNA by qRT-PCR (A) and total CRTh2 protein by western blot and densitometry analysis (B). CRTh2 surface levels were determined by flow cytometry following DEX and/or PPT treatment (C) or DEX and/or E2 treatment $(0.1 \mu \mathrm{M}, \mathrm{D})$. The effect of DEX and PPT on CRTh2 transcriptional activity was assessed using a CRTh2-pro/Luc reporter construct (E).GC, glucocorticoid; $D E X$, dexamethasone; PPT, propyl pyrazole triol (ER $\alpha$ selective agonist); EPa , estrogen receptor alpha; E2, $\beta$-estradiol. ${ }^{*} P<0.05$ vs vehicle; $\#<<$ 0.05 vs DEX, determined by One Way RM ANOVA

Figure $4 \mathrm{GC}$ and estrogen receptor signaling enhance type 2 cytokine release following treatment with $\mathrm{PGD}_{2}$. In vitro differentiated Th2 cells pre-treated (24 hours) with DEX $(0.1 \mu \mathrm{M})$ and/or PPT $(10 \mu \mathrm{M})$ were assessed by ELISA for IL-5 (A) and IL-13 (B) release following stimulation with the CRTh2 ligand $\mathrm{PGD}_{2}$ (24 hours). $G C$, Glucocorticoid; $D E X$, dexamethasone; $P P T$, propyl pyrazole triol (ER $\alpha$ selective agonist); $P G D_{2}$, Prostaglandin $\mathrm{D}_{2} ; E P a$, estrogen receptor alpha. ${ }^{*} P<0.05$ vs vehicle; ${ }^{\#} P<0.05$ vs DEX, determined by One Way RM ANOVA

\section{Hosted file}

Merged Figures Nov 17.pdf available at https://authorea.com/users/447215/articles/546247dual-activation-of-estrogen-receptor-alpha-and-glucocorticoid-receptor-upregulate-crth2mediated-type-2-inflammation-mechanism-driving-asthma-severity-in-women

\section{Hosted file}

Asthma in Women - Tables March 12.docx available at https://authorea.com/users/447215/ articles/546247-dual-activation-of-estrogen-receptor-alpha-and-glucocorticoid-receptorupregulate-crth2-mediated-type-2-inflammation-mechanism-driving-asthma-severity-in-women 